\title{
Olfactory bulb resection and water intake in the white rat'
}

\author{
W. B. VAHCE \\ INDIANA UNIVERSITY
}

Bilateral transection of the olfactory bulbs in rats abolishes drinking in response to sodium loads but does not affect ad lib water intake, body weight, urine output, sodium chloride preference, or increased sodium intake with desoxycorticosterone treatment.

Novakova \& Dlouha (1960) reported an increased water intake in rats with bilateral transections of the olfactory bulbs, and Sundsten \& Sawyer (1959) found distinctive electrophysiological changes in the olfactory bulbs of dogs in response to intracarotid injections of hypertonic saline and sucrose. Since the bulb response to hypertonic solutions was not affected by separating the bulbs from the forebrain or by procainization of the olfactory mucosa, it was concluded that the bulb contained osmoreceptive units. The present study reports the effects of olfactory bulb section on water intake in response to hypertonic sodium loads with the aim of clarifying the role of bulb osmoreceptors in water intake.

Method

Eleven male Sprague-Dawley rats weighing between 300 and $350 \mathrm{~g}$ served as Ss. In six experimental animals the skull was opened with a dental burr and the olfactory bulbs bllaterally transected with a scalpel blade. Gross post-mortem observation showed that the bulbs had been completely separated from the forebrain, the cuts being distal enough so as not to involve any of the frontal poles. After a two week recovery period, the six experimental and five control animals were given a $2 \mathrm{ml} / 100 \mathrm{~g}$ load of molar sodium chloride by IP injection, and the water intake was followed for a 2-h post load period. The animals were further tested for sodium chloride (.5\%) preference in a two bottle test and for increased sodium appetite in response to desoxycorticosteron: acetate (DOCA) administration.

\section{Results}

The experimental animals showed a pronounced delay in drinking following the sodium load, drinking no water for the first $40 \mathrm{~min}$ and an average of only
2.5 $\mathrm{ml}$ for the first hour. By contrast, the control animals began drinking in the first $5 \mathrm{~min}$ following the load and consumed an average of $12 \mathrm{ml}$ over the first hour. A $t$ test for the differences in intake for the first hour was significant $(p<.01)$. During the second hour the experimental group had drunk an average of $10 \mathrm{ml}$ as against $16.8 \mathrm{ml}$ for the controls (difference not significant).

No significant differences were found in the preference test for sodium chloride, the response to DOCA, body weight, urine output, or ad lib water intake. Discussion

The results strongly suggest that the electricai activity of the olfactory bulbs in response to hypertonic solutions (Sundsten \& Sawyer, 1959) is important in mediating sodium thirst, since drinking in response to sodium loads is virtually abolished by bulb transection. The drinking that does occur (after a 40-min delay) is probably the result of an osmotic diuresis similar to that seen following urea loads (Gilman, 1937). The results further imply that sodium thirst and thirst resulting from normal dehydration are mediated by separate mechanisms, since ad lib water intake and water intake during food deprivation are unaffected. It is interesting to speculate that the activation of limbic and hypothalamic structures by intracarotid saline injections (Wayner, 1967) results originally from the stimulation of the olfactory bulbs.

\section{References}

Gilman, A. The relation between blood osmotic pressure, fluid distribution and voluntary water intake. Amer. J. Physiol., 1937, $120,323-328$.

Novakova, V., Dlouha, H. Effect of severing the olfactory bulbs on the intake and excretion of water in the rat. Nature, 1960 $186,638-639$

Sundsten, J. W., \& Sawyer, C. H. Electro-encephalographic evidence of osmoreceptive elements in olfactory bulb of dog brain. Proc. Soc. Exp. Biol. Med., 1959, 101, 524-527.

Wayner, M. J. Hypothalamic and limbic system activation during salt arousal of drinking. Psychon. Sci., 1967, 7, 179-180. Note

1. This research was supported by PHS grant NB 05940-01. 